\title{
Affective Aspects of Instruction Librarians' Decisions to Adopt New Teaching Practices: Laying the Groundwork for Incremental Change
}

\section{Elizabeth Galoozis}

\begin{abstract}
This article addresses the question: How do emotions and emotional labor relate to instruction librarians' motivations to adopt new teaching practices? Twelve information literacy instruction librarians were interviewed about their motivations to adopt new teaching practices. An initial round of coding was completed using grounded theory, to surface themes of motivations to adopt new teaching practices. In a second round, the themes were retained while further coding was used to identify language reflective of emotion and affective labor, along with five conditions for human motivation identified by Charles J. Walker and Cynthia Symons: competence, autonomy, worthwhile goal-setting, feedback, and affirmation. Using the results of the analysis, suggestions are made for library managers and administrators to lay the groundwork for developing supportive and collegial environments that encourage incremental change and emotional self-reflection.
\end{abstract}

\section{Introduction}

How do emotions and affective labor relate to instruction librarians' motivations to adopt new teaching practices? This question explores the emotional and affective aspects of a research question I examined in previous work. In that work, I analyzed interviews with academic librarians teaching information literacy instruction (ILI), addressing this research question: "What influences librarians to adopt new teaching practices?"1 New practices were not equated with best practices; the aim of the research was to explore openness to risk and change, which led quite naturally into further inquiry into the emotions and emotional labor associated with risk and change. In this article, I undertake the task laid out by Celene Seymour in an ethnographic study of information literacy librarians, of "exploring the emotional terrain associated with information literacy instruction and improving this environment," which in Seymour's judgment "should maximize the impact of instruction by minimizing negative instructional experiences." ${ }^{2}$

\section{Literature Review}

Literature that informed the original research question of librarians' motivations to adopt new teaching practices was drawn from the larger educational literature as well as library and in- 
formation science (LIS) literature. Several authors have identified theories of motivation that apply to the adoption of new and/or effective teaching practices by teachers at various levels, including:

- expectancy theory, a theory of internal motivation that calculates individual motivation through ratios of effort-to-performance and performance-to-outcome ${ }^{3}$

- House's Path-Goal leadership model, which focuses on how leaders can motivate by eliminating barriers to goal achievement and providing clearer paths to goals ${ }^{4}$

- Fullan's Change Theory, which identifies seven external factors that influence adoption of technological changes in pedagogy, including community and administrative support ${ }^{5}$ More specifically, other authors, such as Nolen, Ward, and Horn ${ }^{6}$ and Green, Chivers, and Mynott ${ }^{7}$ identify factors that contribute to teachers' adoption of new instructional practices, including perceived utility, relationships to people who promote or use those practices, librarians' own teacher identities, and the role of managers or supervisors. Judith Glazer, as well as John M. Rogan and Trevor R. Anderson, ${ }^{8}$ identify other potential factors in the adoption of curricular or teaching changes, including external expectations like accreditation and student ratings, psychological barriers like fear and overload, and gender-based power dynamics.

Librarians' development of their own teacher identities is usually dependent on a combination of formal and informal education and training, and there may be significant gaps. ${ }^{9}$ Scott Walter ${ }^{10}$ describes a wide array of instructional improvement programs and individual strategies for teaching librarians, but notes (as of 2006) that instruction remains a minor part of librarians' training, particularly when compared with faculty in other disciplines. More recently, Laura Bewick and Sheila Corrall ${ }^{11}$ found that librarians in the United Kingdom, most of whom had taken a formal course in pedagogy, felt confident in their pedagogical knowledge, while several other authors have described institution-based programs and communities of practice that have shown promise in developing librarians as teachers. ${ }^{12}$

The second round of analysis, presented here, is a response to calls in the LIS and teaching motivation literature for research into emotional and affective aspects of motivation, decision-making, and teaching. For example, Heidi Julien and Shelagh K. Genuis argue that "there is a need for research that seeks [to] identify, understand, and ameliorate barriers to success [for librarians teaching]," and call for "attention to factors which positively influence how all librarians and library workers frame, interpret, and emotionally respond to instructional activities is warranted."13 Sherianne Shuler and Nathan Morgan propose that "a fuller picture of emotional labor in the library context is needed that includes an understanding of the emotions librarians experience and an appreciation of the work that must be done to cope with those emotions." 14 Nolen, Ward, and Horn emphasize the contextual nature of teachers' motivation to learn, indicating an individualized research project rather than a generalized one, like their "four-year person-centered ethnography" of eight novice teachers to which they apply a theoretical framework of learning in social context. ${ }^{15}$ Miriam Matteson and Shelly Miller recommend a research agenda that supplements quantitative research with "qualitative methods that would capture individual accounts of emotional labor."16 And work culture researcher Melissa Gregg posits that "ceasing to see our own work lives as exceptional might have the further benefit of improving our credibility in attempting to speak of the labour of others." 17 In this spirit, the results are not intended to be generalizable, but to contribute one piece to the larger literature, to be read in conjunction with similar studies. 
The terms emotion, emotional and affective labor, and motivation encompass a wide range of meaning. For the purposes of coding and throughout this article, I use the following definitions:

- The function of emotion: "emotions have multiple and quite significant functions in motivating and focusing individual endeavors, social interactions, and the development of adaptive and maladaptive behavior." 18

- Emotional labor: "the awareness of the emotional expressions required of a job, and the strategies used to express those emotions." 19

- Affective labor: "The affective labor needed to sustain social relations of cooperation and civility and to strategically manage emotions for social effect is also an everyday practice that, since it is traditionally privatized and feminized, is not recognized or valued as labor." 20

- Motivation: "the conditions that activate, direct, and sustain behavior."21

\section{Methodology}

The original research for this article took place in 2016; Institutional Review Board approval was secured from the University of Southern California. Participants were sought from libraries in the Greater Western Library Alliance (GWLA), a consortium of 38 research libraries across the United States (http://www.gwla.org/about-gwla). (This was a convenience sample, as the author's institution was participating in another study with GWLA libraries.) All participants selected for inclusion in the study indicated in a screening questionnaire that information literacy instruction (ILI) is one of their primary job responsibilities. The group of participants selected for in-depth interviews were chosen in order to hear from a range of librarians with different experience levels, institution types, and other factors. In all, twelve participants, all librarians at GWLA institutions with primary job responsibilities in ILI, were interviewed via the video-interviewing software Adobe Connect. (See appendices A and B for screening questionnaire and interview questions.) Initial thematic coding of the interview transcripts was completed in early 2017 using nVivo, and those preliminary results were presented in 2017.22 During this initial stage of coding, a grounded theory approach was used to derive themes from the interview transcripts. Three main categories of thematic analysis were identified: barriers to adopting new instructional practices, influences on adopting new instructional practices, and the practices themselves. The categories were retained as frames for further coding around emotion, teaching, and motivation, described below.

In their chapter in Teaching Well and Liking It: Motivating Faculty to Teach Effectively, psychology researchers Charles J. Walker and Cynthia Symons summarize multiple theories of motivation, noting five interdependent themes common to both internal and external motivation. They argue that "all of these elements are needed to support high levels of performance" in college-level teaching. They describe the themes this way: "Human motivation is at its highest when people

1. Are competent,

2. Have sufficient autonomy,

3. Set worthwhile goals,

4. Get feedback, and

5. Are affirmed by others." ${ }^{23}$

These five concepts - competence, autonomy, goal-setting, feedback, and affirmation from others - in combination with language related to emotion, or emotional and affective labor (as 
defined in the Literature Review section), were used to code responses in the second round of coding. This method was an attempt to uncover relationships among motivation, emotional and affective labor, and the original three thematic categories of barriers, influences, and practices. A note on coding emotion-related responses: Ina Fourie and Heidi Julien caution that "Emotions are interpreted by people; displays or expressions of emotional experiences are interpreted by researchers and portrayed in their research findings." ${ }^{24}$ Similarly, this study identifies expressions of emotion solely within the transcriptions of these interviews and do not attempt to interpret tones of voice or facial expressions.

Throughout the analysis, each participant is identified by a pseudonym and a job description similar to their own. Gender-neutral names and the singular pronouns they and them are used intentionally.

The Analysis section that follows has been arranged by the original three thematic categories of barriers, influences, and practices.

\section{Analysis}

\section{Barriers (Negative Motivations) to ILI Librarians Adopting New Practices}

One affective barrier to adopting new practices that was identified by participants was burnout. ${ }^{25}$ Angel, a life sciences librarian, cited burnout on both a day-to-day level and throughout the academic calendar as a barrier: "At the end of the semester, we're all so exhausted, and we're all so tired of teaching... . It's hard to maintain interest in something that's that physically exhausting and mentally exhausting, right? You just need to shut it off." Sam, a humanities librarian, related to emotional exhaustion: "[I]f there is not going to be funding for more people, what can you do? You still have to teach X instruction sessions but teaching five sessions in a week can be very tiring." Pressures of time and understaffing, which additional participants mentioned, can make autonomy and goal-setting (two of Walker and Symons' conditions for motivation) difficult to achieve.

Participants frequently mentioned another one of the conditions for motivation: feedback. Deborah Sheesley notes that "academic teaching librarians are often separated from the results of their labor" and they "may receive little or no positive feedback, ${ }^{26}$ so even a small amount can reinforce or dampen motivation to adopt a new practice. Jess, an outreach librarian, noted a time when a small amount of feedback reinforced instructional decisions:

I had a session the other day that I didn't feel so hot about cause I couldn't read the teacher, like I just couldn't read if she was like happy with the session or not. And then she wrote this really nice email after and she's like, this session was great...I had no idea, if she never said that I would've walked away thinking that session was just like, eh, not the best I've ever done.

Seeking formal feedback through assessment can be a challenge as well; Sam, a humanities librarian, said:

I'm having a hard time conceptualizing sort of what one might assess meaningfully in a one-shot context so I kind of read about assessment but I'm shy to try it out because it seems like we'd need more infrastructure for it to give us meaningful information. 
Several participants worried about appearing competent (another of Walker and Symons' conditions for motivation) in front of both faculty and students when trying something new. For example, Shawn, a science librarian, said, "with professors, it depends on how they see me, and I can't relate to them until I figure out how they see me, and then modify the way I interact with them." Madison, a humanities librarian, felt they hadn't built enough capital or logged enough time at a new job to try new things, and had put "big, drastic changes on the back burner." Celene Seymour's interviews with information literacy librarians also point to tensions with instructing faculty as barriers to change. In that study, "[s]everal participants report it is difficult to convince library faculty to upset the status quo," partly due to lack of acceptance as equals by non-library faculty members." ${ }^{27}$

Some participants found it difficult to prioritize their goals of trying new things among the pressures of others' perceptions and time, and within the formal structures of work and reward, which, as Lisa Sloniowski notes, tend to value "the glorification of concrete outputs in performance measurements over emotional labor." ${ }^{28}$ Underlining the need for incremental rather than sudden or transformational change, several participants referred to the need for iterative feedback over time, to be able to be motivated to create meaningful change in their instructional practices. While this was valuable to individual librarians' motivation and practice, Angel, a life sciences librarian, noted that, in their particular tenure program, they were not encouraged "to make tiny changes along the way." Sasha, a medical librarian, contrasted the effort of adopting new ILI practices with the recognition offered in college and university accreditation processes and other reward structures:

You will sometimes find critical thinking [in accreditation documentation] or something that you can kind of piece out and tease out and go okay, they're talking about information literacy here but...do you have that relationship with that college... that takes a lot of relationship-building that a lot of people don't have time for.

This observation echoes a participant in Seymour's study, who "reported that she has no formal authority to promote change or authority to influence the integration of information literacy instruction except the power of influence." ${ }^{29}$ Influence takes time and emotional labor to build and wield.

\section{Influences on ILI Librarians' Adoption of New Teaching Practices}

Participants cited many different influences, from self-talk to institutional norms, related to emotion and emotional labor. One influence was the presence of, or desire for, a feeling of affirmation, one of Walker and Symons' conditions for motivation. Hearing success stories from other librarians, for example, was an often-mentioned influence, both informally on a local level and through professional reading and exchanges like conferences. Specifically, Val, a head of instruction and outreach, said they valued "seeing how other people put it into practice, seeing some evidence of success." Jess, an outreach librarian, said, "being able to talk about why they did things after the session took place, or like, where that came from and makes a huge impact on my motivation and my interest in trying out different stuff." These responses align with Eamon Tewell's conclusion in his study of librarians' adoption of critical information literacy practices: "Librarians need to not just see that this approach to teaching [i.e., experimentation] works for them and their students, but to be supported in their efforts." ${ }^{30}$ 
Participants also pointed to their own sense of competence (another condition for motivation), as developed through experiences inside and outside the library, as an influence. A few participants drew on expertise from previous educational experiences, such as a PhD program, or a prior career as an elementary school English instructor. Ari, an information literacy librarian, described an iterative process of "tossing everything out and starting from scratch," which they felt competent about having learned from previous experience:

Having done that four or five times over the course of my librarian instructional career, at least I feel like I'm in a position where I actually do have something that's fairly solid and practical and that I can, in good conscience, propagate to the other librarians.

This feeling of solidity and good conscience has been built over years - and is not easily measured - but completely shapes this participant's approach to incorporating instructional different practices into their program. Work culture researcher Melissa Gregg identifies the affective labor involved in this type of cyclical work as the "formation of somatic and psychic strategies appropriate for positions and workloads that have no definitive beginning or end," and notes that this type of "preparatory labour...is part of the wider requirement placed on white-collar workers to continually demonstrate their ongoing employability." 31

A feeling of autonomy in the classroom and in choosing one's instructional goals was crucial to participants' motivations to adopt new instructional practices. Participants often spoke about autonomy in conjunction with feelings of commitment and support, affective labor that Lisa Sloniowski describes as "reproductive in its own right, if not generally recognized or valued in university retention-assessment schemes and mechanisms." 32 Jun, an instruction librarian, literally "felt good" about having autonomy to create a different kind of relationship with students: "I have the ability to...go beyond the bounds of I am the authority, you are the student... it allows me to really feel good sometimes about what it is I'm teaching." Robin, a humanities librarian, focused on autonomy within restriction: "I'm really 110 percent committed to information literacy... we have a lot of structural issues, like the one-shot... I feel like there's ways we can work around that by working more with faculty and designing."

\section{Practices Implemented by ILI Librarians}

Participants associated competence with what information literacy librarian Ari termed "adequate preparation." Ari put it this way:

When you don't have adequate preparation, my fallback is to talk the whole time, which I can do well to a certain point, but it leaves a bad taste in my mouth and it's not something that I want to make a long practice of.

When many participants adopted new practices, they wanted to feel comfortable with them ahead of implementing them with students. Kit, a digital scholarship librarian, valued a significant amount of preparation: 
I am never confident if I don't prepare well. It's not like a prideful, I'm awesome kind of thing. It's I put a ton of time into preparing for a class... if you've prepared your content so well...it's just so deep in you, and you know it so well.

These comments also align with Walker and Symons' condition for motivation of setting meaningful goals - keeping a long view of one's practices and preparing deeply were long-term goals that kept these participants engaged in the work of improving instructional practices. Life sciences librarian Angel articulated the goal of aligning with students' affective experiences of research: "When I take examples on the fly, sometimes they work well, sometimes they don't, which is a lesson in itself, right; that you have to struggle with your keywords, and with exploring a topic, and really thinking about it." This comment demonstrates both application and modeling of the affective labor involved in teaching and learning.

Nolen, Ward, and Horn point out that teaching decisions are not made in a vacuum: "Individual teachers' goals and values must be, in some way, reconciled with the joint enterprises of their teaching community of practice." ${ }^{33}$ Most participants emphasized the value of building relationships with colleagues through getting feedback from them, as well as students, on teaching. Angel, a life sciences librarian, said in particular of new approaches:

I think it's great when you team-teach and you can debrief after, especially if it's a new workshop or a new kind of instruction session that you haven't really tried out before. Debriefing is so critical, particularly right after it happens, because I think we work in environments where we're off to the next thing immediately, whether it be a meeting or even just having to go to another session.

Feedback from students and colleagues, time to reflect, and the ability to set significant, emotionally connected goals were all identified by participants as crucial to making meaningful changes in their instructional practices. Participants consistently valued this type of foundation over trying a teaching "trick" or new technology. Several participants spoke of using a "menu" or "toolbox" of methods to accommodate changing needs and instructional situations. Jordan, a library fellow, said, "I'll apply the learning objective that I think would best fit the class, and sometimes I'll make up a new one if I feel like my menu doesn't fit any of them, or I'll kind of modify the ones I have." Digital scholarship librarian Kit said their goals were guided by the question: "what do the students need and then how can I change my teaching to meet their needs the best way?" This kind of reflection and goal-setting seemed to be vital in laying the groundwork for motivating librarians to adopt new instructional practices.

\section{Recommendations}

At the end of their ethnographic study of information literacy librarians, Celene Seymour concludes:

All librarians who deal with the public directly, such as reference and circulation staff, face... "emotional labour" of providing service with a smile even at the most trying times and with the most trying patrons. But instruction librarians may face a different kind of emotional toll which requires proactive responses such 
as better preparation for and support for their instructional responsibilities and a greater understanding of the emotional issues they face that stand in the way of their success. ${ }^{34}$

The participants in this study directly address the need for a proactive rather than reactive approach to the emotions and emotional labor involved in learning about, reflecting on, and incorporating new teaching practices. The results of this study confirm the suggestions of Julien and Genuis that "workplace managers can influence instructional success by demonstrably valuing instruction work, and by providing emotional support, as well as on-the-job training." ${ }^{35}$ In light of the words and experiences of the participants in this study, what might this look like?

For one, it looks like allowing more time for reflection on, and sharing of, instructional experiences. While participants observed that this happened sometimes in departmental meetings or at conferences, all emphasized the need for more time for reflection-clearly necessary for creating the conditions for adopting new instructional practices. Administrators and coordinators in a position to create time and space for reflection should use their power to do so. This will take different forms in different contexts and for different types of people-librarians can reflect through self-reflection, engaging in conversation or peer review within communities of practice, or experimenting in the classroom.

Another recommendation is to value expertise and learning in the areas of affective and emotional labor. This may mean organizing skill-shares, pairing librarians with mentors who focus on emotional labor, or building assessment of emotional competence or emotional reflection into hiring and evaluation processes. Yet another is to value what life sciences librarian Angel characterized as "tiny changes along the way," rather than focusing exclusively on radical or high-impact changes to teaching practices. This value could be applied through observation programs or learning communities that highlight smaller-scale changes and reward them.

Readers are encouraged to reflect on their own institutional and instructional contexts. What space can be made for these reflections and conversations? How can you put into place the conditions for motivation, and embody valuing the affective and emotional labor inherent in adopting new instructional practices?

\section{Conclusion}

While these findings are not generalizable, they may be useful in conjunction with similar studies and examination of local contexts. More research is needed that highlights the voices, emotions, and processes of ILI librarians, to complement the myriad practical resources available. Additional directions for research may include explorations of: the managerial and structural suggestions above; issues of power and privilege, such as race, gender identity, and disability; and personal consequences of trying new things in the classroom that threaten the status quo. Other methods are also needed to complement the qualitative interview approach used here-a large-scale survey, for example, or analysis of already published stories and perspectives. In highlighting the experiences of these participants, I hope to have added to the understanding of ILI librarians' decision-making and motivation, so that instructional programs can be strengthened. 


\section{Acknowledgements}

I am very grateful to the participants in this study for sharing their time and thoughts. I am indebted to the leaders and scholars of the Institute for Research Design \& Librarianship for their instrumental role in shaping and supporting this research. In particular, I would like to thank Justin de la Cruz, Lee Ann Fullington, Don Jason, Marie Kennedy, Lili Luo, Cynthia Orozco, Eamon Tewell, and Brandon West. Many thanks to Carolyn Caffrey and Caro Pinto for reviewing earlier drafts. Interview transcription was funded by a Southern California Electronic Libraries Consortium Research Incentive Grant. 


\section{APPENDIX A. Screening Questionnaire}

The objective of this questionnaire is to identify a sample of academic librarians with information literacy instruction responsibilities for in-depth interviews.

If you are selected to participate in the interview stage of the study, you will receive another email requesting your participation. Because your responses to the questionnaire will be examined in conjunction with the interview, anonymity cannot be guaranteed.

This questionnaire should take no longer than 10 minutes to complete.

1. At which GWLA (Greater Western Library Alliance) member institution are you currently employed as a librarian? If you are not currently employed as a librarian at a GWLA institution, please exit this study.

(dropdown menu of all GWLA institutions)

2. Do you consider information literacy instruction one of the primary responsibilities of your job?

$\square$ Yes

$\square$ No

3. How many years have you been working as a professional librarian? Please enter a whole number (example: 5).

4. Do you have a master's degree in library and/or information science?

$\square$ Yes

$\square \quad$ No

5. Please list any other degrees (including bachelor's level) you have, and their subjects (examples: Bachelor's in psychology, MFA in music)

6. How would you rate your familiarity with current trends, developments, and publications in information literacy instruction?

$\square \quad$ Very unfamiliar

$\square$ Somewhat unfamiliar

$\square$ Somewhat familiar

$\square$ Very familiar

7. In general, which statement best describes how you feel about participating in information literacy instruction?

$\square \quad$ I rarely enjoy it

$\square \quad$ I do not enjoy it most of the time

$\square \quad$ I enjoy it most of the time

$\square \quad$ I almost always enjoy it

$\square \quad$ Other (with text entry) 
8. How would you rate your interest in incorporating new methods and/or theories into your information literacy instruction practices?

Very high

$\square$ Somewhat high

$\square$ Somewhat low

$\square$ Very low

9. How many years have you been working at your current institution? Please enter a whole number (example: 5).

10. How many people at your institution's library(ies) have information literacy instruction as one of their primary job responsibilities?

1-5

$6-15$

16-30

31-50

․ 51 or more

11. Do librarians at your institution receive tenure or an equivalent designation?

$\square$ Yes, and I have received it

$\square$ Yes, and I have not received it

$\square$ No

Other (with text entry)

12. Does your institution have a Center for Teaching Excellence, or a similar office that promotes and provides training for improving teaching?

$\square$ Yes

$\square$ No

$\square$ Not sure

13. Have you received any training of any kind from that office?

口 Yes

$\square$ No

$\square$ Not sure

Please enter your name, position title, and email if you are interested in being contacted for a follow-up interview. 


\section{Appendix B. Interview Guide}

\section{Introduction}

Thank you so much for participating in this study. As a reminder, the objectives of this study are to:

- Describe current information literacy instructional practices of academic librarians

- Identify the most common influences on academic librarians' decisions about information literacy instruction practice

- Identify barriers to adopting new information literacy instruction practices

- Determine if there is a correlation between librarians' adoption of information literacy instruction practices they have not previously employed and other factors (for example, self-perception of teaching efficacy or institutional culture)

The interview should take no longer than 75 minutes. I want to assure you that our conversation will be kept confidential, and that any publication resulting from this study will aggregate and anonymize responses.

Before we begin, do you have any questions about the consent process, the study, or the interview itself?

I'm going to press the Record button now.

I'm going to start by asking some questions about your teaching.

\begin{tabular}{|c|c|}
\hline Question & Purpose \\
\hline $\begin{array}{l}\text { 1. Please define "information literacy instruction" in your } \\
\text { own words. }\end{array}$ & $\begin{array}{l}\text { Establish baseline definition; determine if } \\
\text { different types of definitions contribute to } \\
\text { greater flexibility or openness to change }\end{array}$ \\
\hline $\begin{array}{l}\text { 2. Describe the kinds of information literacy instruction } \\
\text { you do as part of your work. } \\
\text { a. [Probe] Do you teach any for-credit classes? Classes } \\
\text { outside the library? }\end{array}$ & $\begin{array}{l}\text { Describe the variety of activities that fall } \\
\text { under ILI; compare librarians who teach in } \\
\text { different subject areas and with different } \\
\text { types of students (or for-credit classes) }\end{array}$ \\
\hline $\begin{array}{l}\text { 3. Please tell me about your planning process for a } \\
\text { typical information literacy instruction session. How } \\
\text { do you decide what type of teaching method or } \\
\text { approach to take? } \\
\text { a. [Probe] What factors go into those decisions? } \\
\text { b. How much planning time do you take for each } \\
\text { hour of instruction? }\end{array}$ & $\begin{array}{l}\text { Investigate how much variety librarians } \\
\text { engage in for different classes or audiences, } \\
\text { or even the same class multiple times; list } \\
\text { influences on planning process }\end{array}$ \\
\hline $\begin{array}{l}\text { 4. How do you reflect on your information literacy } \\
\text { instruction? } \\
\text { a. [Probe] Are you required to reflect on, or assess, } \\
\text { teaching in a systematic way? }\end{array}$ & $\begin{array}{l}\text { Determine if required and/or nonrequired } \\
\text { reflection and assessment have a bearing on } \\
\text { decisions about ILI }\end{array}$ \\
\hline
\end{tabular}

Thanks so much. Now I'm going to ask some questions about considering new practices in your information literacy instruction. These could be small changes, such as using different kinds of example topics in a class, or large ones, such as using active learning in all your classes. 


\begin{tabular}{|l|l|}
\hline \multicolumn{1}{|c|}{ Question } & \multicolumn{1}{c|}{ Purpose } \\
\hline $\begin{array}{l}\text { 5. How do you find out about information literacy instruction } \\
\text { practices, activities, or theories that are new to you? }\end{array}$ & $\begin{array}{l}\text { Determine if low exposure, or } \\
\text { different types of exposure, lead } \\
\text { to adoption of new practices }\end{array}$ \\
\hline $\begin{array}{l}\text { 6. Please describe a time when you considered a new practice in } \\
\text { your information literacy instruction (such as active learning or } \\
\text { assessment) and adopted it. Why? }\end{array}$ & $\begin{array}{l}\text { Describe an example of } \\
\text { influences on adoption of a new } \\
\text { practice }\end{array}$ \\
\hline $\begin{array}{l}\text { 7. Now describe a time when you considered a new practice in } \\
\text { your information literacy instruction (such as active learning or } \\
\text { assessment) but decided not to adopt it. Or, this could be a time you } \\
\text { tried something and decided not to try it again. Why? }\end{array}$ & $\begin{array}{l}\text { Describe an example of } \\
\text { influences against adoption of a } \\
\text { new practice }\end{array}$ \\
\hline $\begin{array}{l}\text { 8. In general, what convinces you to adopt a new practice in your } \\
\text { information literacy instruction? }\end{array}$ & $\begin{array}{l}\text { Describe general influences on } \\
\text { adoption of new practices }\end{array}$ \\
\hline
\end{tabular}

In this last section, I'll ask you about different influences on you as a teacher.

\begin{tabular}{|l|l|}
\hline \multicolumn{1}{|c|}{ Question } & \multicolumn{1}{c|}{ Purpose } \\
\hline $\begin{array}{l}\text { 9. Please describe the structure of the instruction or information } \\
\text { literacy program in your library or library system. For example, is } \\
\text { there a coordinator of instruction? } \\
\begin{array}{l}\text { a. [Probe] What role do you play in your information literacy } \\
\text { program? [Do you supervise others?] }\end{array}\end{array}$ & $\begin{array}{l}\text { Determine organizational } \\
\text { influences on adoption of new } \\
\text { practices }\end{array}$ \\
$\begin{array}{l}\text { b. [Probe] Would you characterize your information literacy } \\
\text { program as a community of practice? To what degree do } \\
\text { librarians learn from each other or from outside observers } \\
\text { (including peer observation and disciplinary instructors)? }\end{array}$ & \\
$\begin{array}{l}\text { c. [Probe] How about mentoring? } \\
\text { d. [Probe] How does communication happen among instructing } \\
\text { librarians in your information literacy program? }\end{array}$ & \\
\hline $\begin{array}{l}\text { 10. How were you trained in information literacy instruction? Please } \\
\text { include both formal and informal forms of education, reading, and } \\
\text { training. [possible probes: teaching centers on campus, workshops, } \\
\text { Immersion, was it fits \& starts or continuous?] }\end{array}$ & $\begin{array}{l}\text { Determine correlation of } \\
\text { adoption of new practices with } \\
\text { type and level of ILI training }\end{array}$ \\
\hline $\begin{array}{l}\text { 11. How confident do you feel as a teacher? } \\
\text { questionnaire here.] Is there anything else you'd like to share with } \\
\text { me about your information literacy instruction experiences? }\end{array}$ & $\begin{array}{l}\text { Clarify unclear or surprising } \\
\text { questionnaire answers }\end{array}$ \\
\hline $\begin{array}{l}\text { 12.Describe any other pressures or influences on you related to making } \\
\text { decisions about information literacy instruction. }\end{array}$ & $\begin{array}{l}\text { Gather any information not } \\
\text { covered in questionnaire or } \\
\text { interview }\end{array}$ \\
\hline $\begin{array}{l}\text { 13. [Follow up on any question-provoking answers to screening } \\
\text { confidence as a teacher }\end{array}$ \\
\hline
\end{tabular}

Thank you so much for generously sharing your time and thoughts with me. If there is anything you'd like to add, please feel free to contact me. I'm hoping to publish the results of this study eventually; if that happens, would you be interested in being notified?

Thanks again, and have a great day. 


\section{Notes}

1. Elizabeth Galoozis, "When to Plant Heirlooms and When to Plant Hybrids: Unearthing Instruction Librarians' Motivations for Adopting New Practices" (presented at LOEX Conference, Lexington, KY, May 11-13, 2017).

2. Celene Seymour, "Ethnographic Study of Information Literacy Librarians' Work Experience: A Report from Two States," in Transforming Information Literacy Programs: Intersecting Frontiers of Self, Library Culture, and Campus Community, eds. Carroll Wetzel Wilkinson and Courtney Bruch (Chicago, IL: Association of College and Research Libraries, 2012), 26.

3. Charles J. Walker and Cynthia Symons, "The Meaning of Human Motivation," in Teaching Well and Liking It: Motivating Faculty to Teach Effectively, ed. James L. Bess (Baltimore, MD: The Johns Hopkins University Press, 1997), 3-18.

4. Elizabeth F. Purmton and Elmore R. Alexander, “Obtaining Faculty Motivation and 'Buy In' to a Major Program Change: A Case Study in Assessment," Business Education Innovation Journal 5, no. 1 (June 2013): 53-57.

5. Cynthia Gautreau, "Motivational Factors Affecting the Integration of a Learning Management System by Faculty," Journal of Educators Online 8, no. 1 (2011): 1-25.

6. Susan Bobbitt Nolen, Christopher J. Ward, and Ilana Seidel Horn, "Changing Practice(s): A Situative Account of Teachers' Motivations to Learn," in Teacher Motivation: Theory and Practice, eds. Paul Richardson, Stuart A. Karabenick, and Helen M.G. Watt (London, UK: Routledge, 2014), 167-81.

7. Jamie Green, Barbara Chivers, and Glen Mynott, "In the Librarian's Chair: An Analysis of Factors Which Influence the Motivation of Library Staff and Contribute to the Effective Delivery of Services," Library Review 49 , no. 8 (2000): 380-86.

8. Judith Glazer, "Beyond Male Theory: A Feminist Perspective on Teaching Motivation," in Teaching Well and Liking It: Motivating Faculty to Teach Effectively, ed. James L. Bess (Baltimore, MD: The Johns Hopkins University Press, 1997), 37-54; John M. Rogan and Trevor R. Anderson, “Bridging the Educational Research-Teaching Practice Gap: Curriculum Development, Part 2-Becoming an Agent of Change," Biochemistry and Molecular Biology Education 39, no. 3 (2011): 233-41.

9. Rebecca Albrecht and Sara Baron, "The Politics of Pedagogy: Expectations and Reality for Information Literacy in Librarianship," Journal of Library Administration 36, no. 1/2 (2008): 71-96; Theresa Westbrock and Sarah Fabian, "Proficiencies for Instruction Librarians: Is There Still a Disconnect Between Professional Education and Professional Responsibilities?" College E Research Libraries 71, no. 6 (2010): 569-90; Trevor Austin and Janine Bhandol, "The Academic Librarian: Buying Into, Playing Out, and Resisting the Teacher Role in Higher Education," New Review of Academic Librarianship 19, no. 1 (2013): 15-35; Dani Brecher and Kevin Michael Klipfel, "Education Training for Instruction Librarians: A Shared Perspective," Communications in Information Literacy 8, no. 1 (2014): 43-49; Laura Saunders, "Education for Instruction: A Review of LIS Instruction Syllabi," Reference Librarian 56, no. 1 (2015): 1-21; Amanda Kathryn-Nichols Hess, "From Information Experts to Expert Educators? Academic Librarians' Experiences with Perspective Transformation and Their Teaching Identities" (PhD dissertation, Oakland University, 2017); Lauren Hays, "Academic Librarians' Teacher Identity Development through the Scholarship of Teaching and Learning: A Mixed Methods Study" (PhD dissertation, Northwest Nazarene University, 2018).

10. Scott Walter, "Instructional Improvement: Building Capacity for the Professional Development of Librarians as Teachers," Reference E User Services Quarterly 45, no. 3 (2006): 213-18.

11. Laura Bewick and Sheila Corrall, "Developing Librarians as Teachers: A Study of Their Pedagogical Knowledge," Journal of Librarianship and Information Science 42, no. 2 (2010): 97-110.

12. Emily Mazure, Nicole Scholtz, and Maura Seale, "An Outcome-Based Evaluation Of the University of Michigan University Library Instructor College" (2007), available online at https://www.lib.umich.edu/files/SI623report. pdf [accessed 26 November 2018]; Kimberly Davies-Hoffman et al., "Keeping Pace with Information Literacy Instruction for the Real World: When Will MLS Programs Wake Up and Smell the LILACs?" Communications in Information Literacy 7, no. 1 (2013): 9-23; Malia Willey, "Library Instructor Development and Cultivating a Community of Practice," in Advances in Librarianship 38, eds. Anne Woodsworth and W. David Penniman (London, UK: Emerald Group Publishing Limited, 2014), 83-100; Rachel Gammons, Lindsday Inge, and Alexander Carroll, "Sharing Our Success: Using a Teacher Training Program to Improve Information Literacy Instruction and Support MLIS Students" (paper, Association of College \& Research Libraries Conference, Baltimore, MD, Mar. 2017); April D. Cunningham and Carrie Donovan, "Settling Uncharted Territory: Documenting \& Rewarding Librarians' Teaching Role in the Academy," in Transforming Information Literacy Programs: Intersecting Frontiers of Self, Library Culture, and Campus Community, eds. Carroll Wetzel Wilkinson and Courtney Bruch (Chicago, IL: 
Association of College \& Research Libraries, 2012), 181-219.

13. Heidi Julien and Shelagh K. Genuis, "Librarians' Experiences of the Teaching Role: A National Survey of Librarians," Library \& Information Science Research 33, no. 2 (2011): 109.

14. Sherianne Shuler and Nathan Morgan, "Emotional Labor in the Academic Library: When Being Friendly Feels Like Work," Reference Librarian 54, no. 2 (Apr. 2013): 121-22.

15. Nolen, Ward, and Horn, "Changing Practice(s)," 167.

16 Miriam L. Matteson and Shelly S. Miller, "A Study of Emotional Labor in Librarianship," Library and Information Science Research 35, no. 1 (2013): 60.

17. Melissa Gregg, "Working with Affect in the Corporate University," in Working with Affect in Feminist Readings: Disturbing Differences, eds. Marianne Liljeström and Susanna Paasonen (London, UK: Routledge, 2010), 187.

18. Carroll E. Izard, “The Many Meanings/Aspects of Emotion: Definitions, Functions, Activation, and Regulation," Emotion Review 2, no. 4 (2010): 368.

19. Miriam L. Matteson and Shelly S. Miller, "Emotional Labor in Librarianship: A Research Agenda," Library and Information Science Research 34, no. 3 (2012): 176.

20. Lisa Sloniowski, "Affective Labor, Resistance, and the Academic Librarian," Library Trends 64, no. 4 (Sept. 13, 2016): 655.

21. Walker and Symons, "The Meaning of Human Motivation," 4.

22. Galoozis, "When to Plant Heirlooms and When to Plant Hybrids."

23. Walker and Symons, "The Meaning of Human Motivation," 16-17.

24. Ina Fourie and Heidi Julien, "Ending the Dance: A Research Agenda for Affect and Emotion in Studies of Information Behaviour" (paper, ISIC: The Information Behaviour Conference, Leeds, UK, Sept. 2-5, 2014).

25. Matteson and Miller define job burnout through three "related but distinct states": emotional exhaustion, cynicism, and "reduced professional accomplishment or efficacy." (Matteson and Miller (2013), 55.)

26. Deborah F. Sheesley, "Burnout and the Academic Teaching Librarian: An Examination of the Problem and Suggested Solutions," Journal of Academic Librarianship 27, no. 6 (November 2001): 448.

27. Seymour, "Ethnographic Study of Information Literacy Librarians' Work Experience," 27.

28. Sloniowski, "Affective Labor, Resistance, and the Academic Librarian," 27.

29. Seymour, "Ethnographic Study of Information Literacy Librarians' Work Experience," 27.

30. Eamon Tewell, "Putting Critical Information Literacy into Context: How and Why Librarians Adopt Critical Practices in Their Teaching," In the Library with the Lead Pipe (Oct. 12, 2016).

31. Gregg, "Working with Affect in the Corporate University," 187.

32. Sloniowski, "Affective Labor, Resistance, and the Academic Librarian," 651.

33. Nolen, Ward, and Horn, "Changing Practice(s)," 173.

34. Seymour, "Ethnographic Study of Information Literacy Librarians' Work Experience," 28.

35. Julien and Genuis, "Librarians' Experiences of the Teaching Role," 109. 